Supplement of Biogeosciences Discuss., 11, 15945-15989, 2014

http://www.biogeosciences-discuss.net/11/15945/2014/

doi:10.5194/bgd-11-15945-2014-supplement

(C) Author(s) 2014. CC Attribution 3.0 License.

(c) (i)

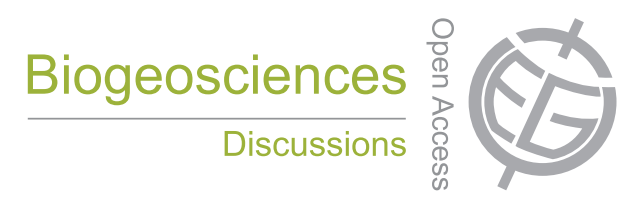

Supplement of

\title{
Organic matter quality of deep permafrost carbon - a study from Arctic Siberia
}

\section{J. Strauss et al.}

Correspondence to: J. Strauss (jens.strauss@awi.de) 


\section{Supplementary methods \\ 1.1 Grain-size analyses}

To disaggregate the sample and to measure only clastic grains, organic components were removed by adding $35 \%$ hydrogen peroxide three times a week to the samples. The samples were continuously shaken (Innova 2300, New Brunswick) for 6 weeks. The organic-free samples were 'washed' to neutral $\mathrm{pH}$ values by repeated decantation after centrifugation (Heraeus Cryofuge 8500i, Thermo Scientific). Samples were dispersed in $1 \%$ ammonia solution and $1 \mathrm{~g}$ dispersing agent $\left(\mathrm{Na}_{4} \mathrm{P}_{2} \mathrm{O}_{7} \times 10 \mathrm{H}_{2} \mathrm{O}\right)$ and shaken (RS12 Rotoshake, Gerhardt) for at least 5 hours. Finally, each sample was split by a rotary cone sample divider (Laborette 27, Fritsch) and two sub-samples of each main sample were analyzed using a laser particle sizer (LS 200, Beckmann-Coulter). Grain sizes between 0.375 and $1000 \mu \mathrm{m}$ were determined (Fig. 2, S1). Because no grain fractions $>1000 \mu \mathrm{m}$ occurred, there was no need for fraction reintegration. Grain-size calculations were done after Folk and Ward (1957) using Gradistat v8 (Blott and Pye, 2001).

\subsection{Elemental composition}

To determine the total elemental carbon and total nitrogen (TN) content, the samples were freeze-dried (sublimator 3-4-5, Zirbus Technology) and homogenized by grinding (Pulverisette 5 planetary mill, Fritsch) before being measured by a carbon-nitrogen-sulphur analyzer (Vario EL III, Elementar). Two $5 \mathrm{mg}$ sub-samples per sample were taken and encapsulated in two zinc capsules. For ensuring complete oxidation of the sample during measurements $\sim 10 \mathrm{mg}$ of tungsten-(VI)-oxide was added. Background signals were detected by measuring a blank capsule at the beginning and calibration standards after each 20 samples. The quantified measurement accuracy is $< \pm 0.1 \mathrm{wt} \%$. TOC $\mathrm{wt}_{\mathrm{w}}$ was measured with a TOC analyzer (Vario Max C, Elementar). Therefore, depending on the previously measured TC content, up to $100 \mathrm{mg}$ were weighed in a crucible and analyzed. The $\mathrm{C} / \mathrm{N}$ ratio was calculated as the quotient of $\mathrm{TOC}_{\mathrm{wt}} \%$ and $\mathrm{TN}$ values. The volumetric $\mathrm{TOC}$ content $\left(\mathrm{TOC}_{\left.\mathrm{kg} / \mathrm{m}^{3}\right)}\right.$ was calculated according to Strauss et al. (2013).

\subsection{Bulk density and volumetric carbon content}

Bulk density (BD) measurements were performed in two steps; (1) in the field lab by determining the volume of frozen samples with the Archimedes Principle (quantifying the water displaced in a water-filled glass beaker using a balance (FCB 8K0.1, Kern; accuracy $\pm 0.1 \mathrm{~g}$ ), and (2) in the freeze-dried laboratory samples; BD was calculated using equation 1. Estimating the $\mathrm{BD}$ is required to convert the measured-weight-based $\mathrm{TOC}_{\mathrm{wt}} \%$ content per sample to a volume-based value. Thus, the $\mathrm{TOC}_{\mathrm{kg} / \mathrm{m}^{3}}$ was calculated according to equation 2 . 


\subsection{Carbon isotope studies}

Stable TOC carbon isotopes were determined with a Finnigan MAT Delta-S mass spectrometer combined with a FLASH elemental analyzer and a CONFLO III gas mixing system. Before analysis, samples were treated with hydrochloric acid (1.3 molar) and heated at $97^{\circ} \mathrm{C}$ for three hours to remove the carbonate. After that, the samples were washed to a neutral $\mathrm{pH}$ value, dried, and weighed in silver capsules. The sub-sample mass was dependent upon $\mathrm{TOC}_{\mathrm{wt} \%}$ content of each sample. The $\delta^{13} \mathrm{C}$ value was determined by the ratio of ${ }^{13} \mathrm{C}$ to ${ }^{12} \mathrm{C}$ atoms expressed in per mille (\%). In order to quantify the deviations of the ${ }^{13} \mathrm{C} /{ }^{12} \mathrm{C}$ ratios, the international standard Vienna Pee Dee Belemnite (VPDB) is used.

Ages were determined by radiocarbon dating of selected macroscopic plant remains. The present measurements were performed at the Poznań Radiocarbon Laboratory, Poland, using compact carbon accelerator mass spectrometry (AMS) (Goslar et al., 2004). The presented radiocarbon ages are uncalibrated ages; Table 1 includes calibrated ages as well. Radiocarbon ages are given in year before present (a BP).

\section{Supplementary figures}

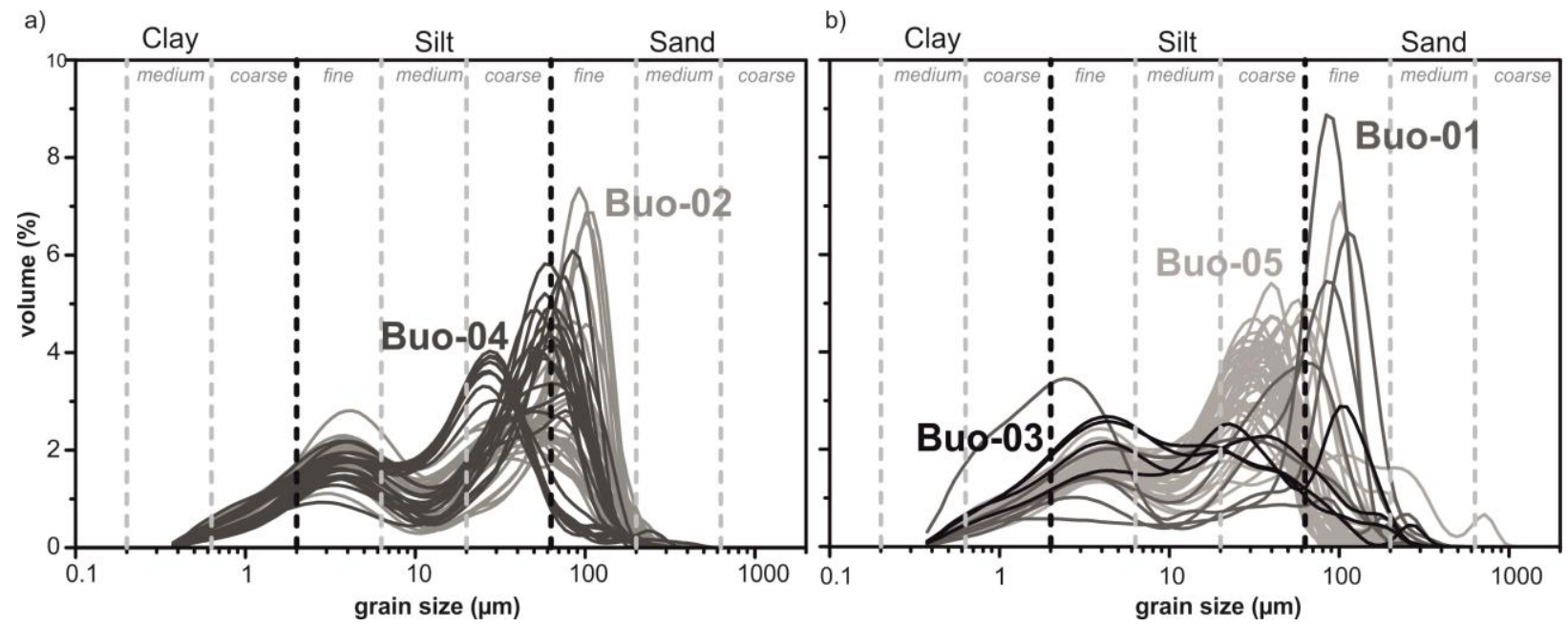

Figure S1. Grain-size distribution of a) Yedoma and b) thermokarst profiles. The different profiles are visualized in different shades of grey. 


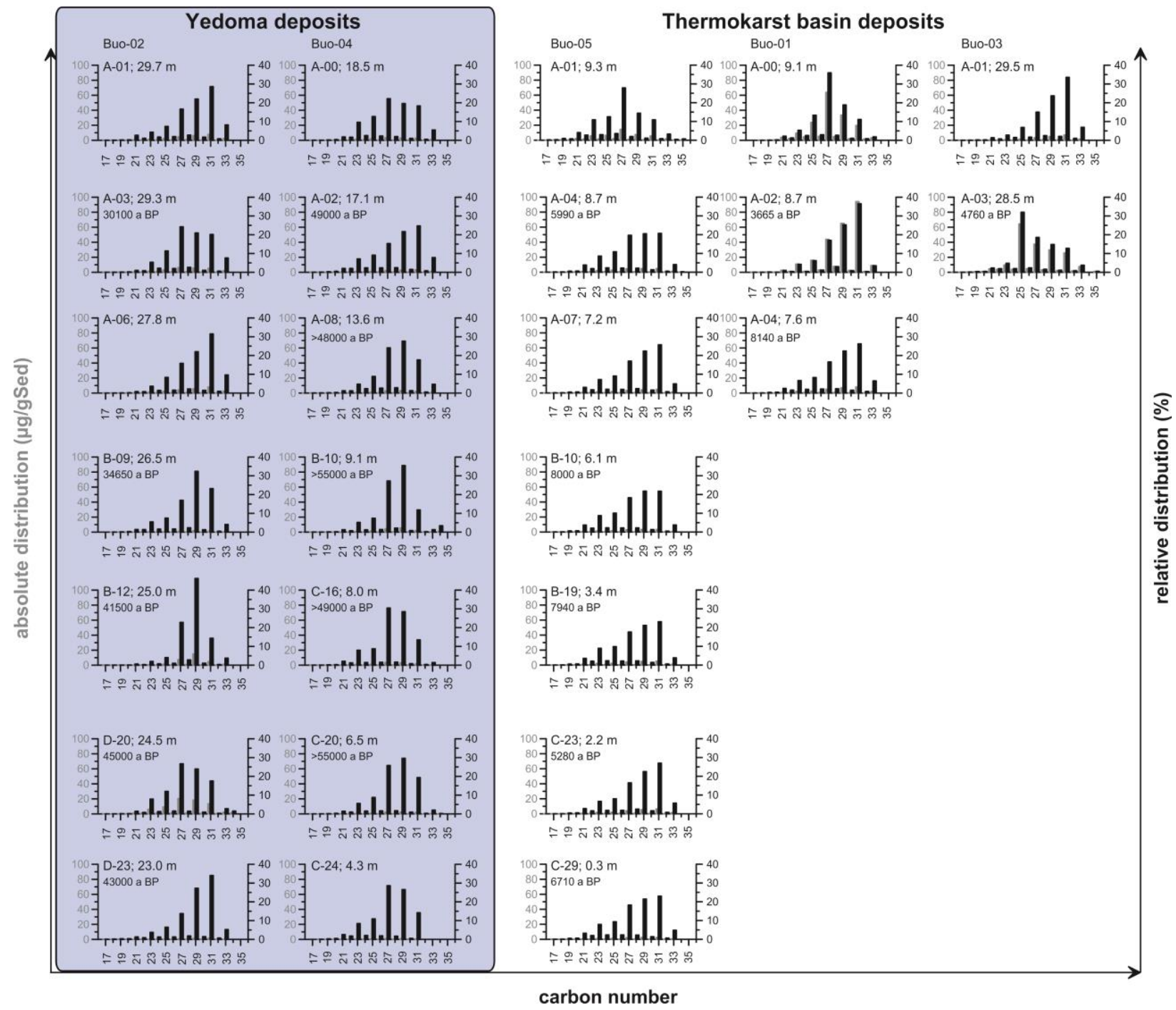

Figure S2. Histogram of the $n$-alkanes. The histograms are sorted stratigraphically from left (old) to right (young). The histograms of the Yedoma deposits are visualized with a blue background. 


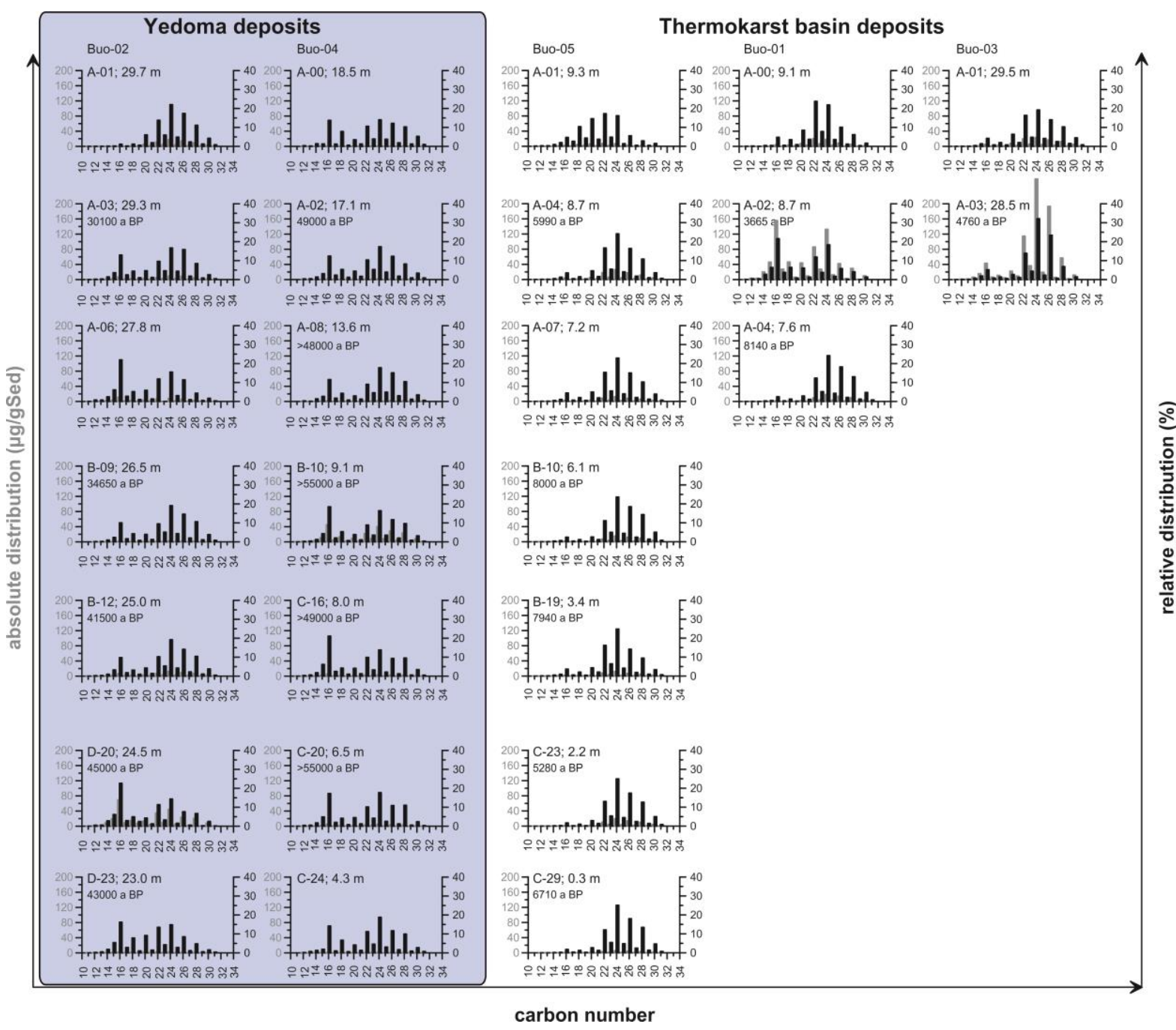

Figure S3. Histogram of the $n$-fatty acids. The histograms are sorted stratigraphically from left (old) to right (young). The histograms of the Yedoma deposits are visualized with a blue background.

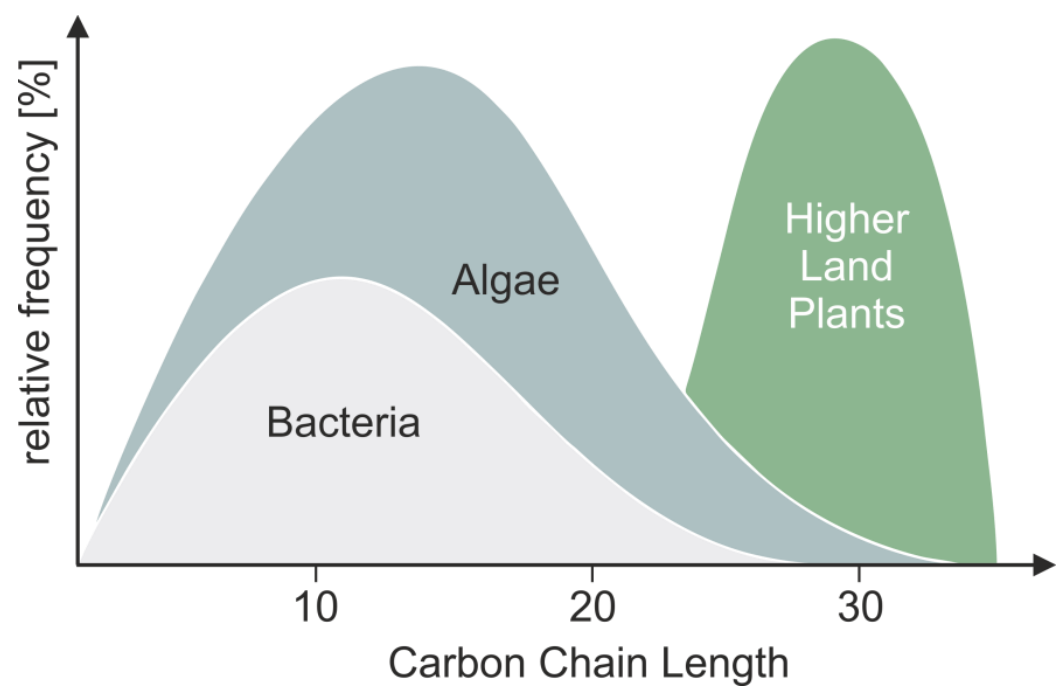

Figure S4. Rough schematic of $n$-alkane chain length in different organisms, after Killops and Killops (2009). 


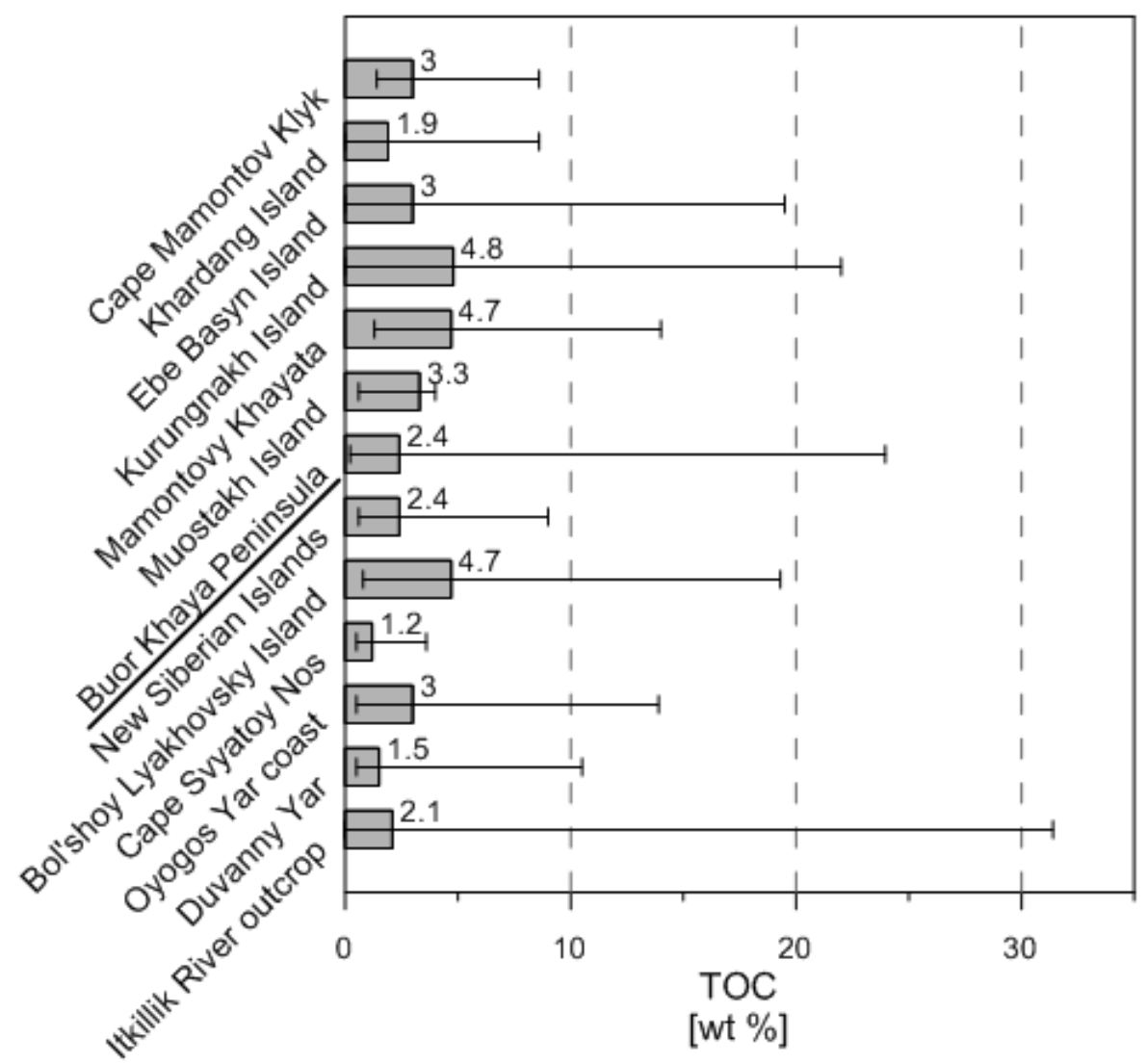

Figure S5. TOC variations from different Yedoma studies sorted from easternmost (Itkillik River, Alaskan North Slope) to westernmost (Mamontov Klyk, western Laptev Sea) studies (Schirrmeister et al., 2008a; Schirrmeister et al., 2008b; Schirrmeister et al., 2011; Strauss et al., 2013), including the present study from Buor Khaya Peninsula. The means are illustrated by the values; the range is shown by the bars.

\section{Supplementary References}

Blott, S. J., and Pye, K.: Gradistat: A grain size distribution and statistics package for the analysis of unconsolidated sediments, Earth Surface Processes and Landforms, 26, 1237-1248, doi:10.1002/esp.261, 2001.

Folk, R. L., and Ward, W. C.: Brazos River bar: A study in the significance of grain size parameters, Journal of Sedimentary Petrology, 27, 3-26, 1957.

Goslar, T., Czernik, J., and Goslar, E.: Low-energy 14c ams in poznań radiocarbon laboratory, poland, Nuclear Instruments and Methods in Physics Research Section B: Beam Interactions with Materials and Atoms, 223-224, 5-11, doi:10.1016/j.nimb.2004.04.005, 2004.

Killops, S. D., and Killops, V. J.: Introduction to organic geochemistry, John Wiley \& Sons, 2009.

Schirrmeister, L., Grosse, G., Kunitsky, V., Magens, D., Meyer, H., Dereviagin, A., Kuznetsova, T., Andreev, A., Babiy, O., Kienast, F., Grigoriev, M., Overduin, P. P., and Preusser, F.: Periglacial landscape evolution and environmental changes of arctic lowland areas for the last 60000 years (western laptev sea coast, cape mamontov klyk), Polar Research, 27, 249-272, doi:10.1111/j.1751-8369.2008.00067.x, 2008a. 
Schirrmeister, L., Grosse, G., Wetterich, S., Overduin, P. P., Strauss, J., Schuur, E. A. G., and Hubberten, H.-W.: Fossil organic matter characteristics in permafrost deposits of the northeast siberian arctic, Journal of Geophysical Research, 116, G00M02, doi:10.1029/2011jg001647, 2011.

Schirrmeister, L., Kunitsky, V. V., Grosse, G., Kuznetsova, T. V., Derevyagin, A. Y., Wetterich, S., and Siegert, C.: The yedoma suite of the northeastern siberian shelf region: Characteristics and concept of formation, Proceedings of the Ninth International Conference on Permafrost, 2, 1595-1601, 2008b.

Strauss, J., Schirrmeister, L., Grosse, G., Wetterich, S., Ulrich, M., Herzschuh, U., and Hubberten, H.-W.: The deep permafrost carbon pool of the yedoma region in siberia and alaska, Geophys. Res. Lett., 40, 6165-6170, doi:10.1002/2013GL058088, 2013. 